\title{
Correspondence
}

\section{Medical Colonialism}

SIR

As final year students at St George's Hospital Medical School, we would like to express our extreme concern over the attitude of the medical profession, particularly the student body, towards elective periods spent abroad in developing countries.

The misconception that the purpose of an elective is to practise one's unpolished skills on an unsuspecting 'bunch of natives', before returning to begin properly, is widespread within the student community. Some even go as far as to assume that the recipient countries ought to be grateful for the help provided by elective students.

We realise that in countries where financial restraints limit the quality of health care, an extra pair of hands, even if unqualified, are often much appreciated. This does not give the student licence to practise medicine in ways which would be illegal in Britain, and are unethical anywhere in the world. Anecdotal evidence of this happening is abundant, and the resulting casualties or deaths go unacknowledged, except in the 'throw away' elective stories back at the Medical School bar.

The problem, which is a real one, comes from the understandable eagerness of students to use the knowledge gained from frustrating years of study within the legal constraints of British medical practice. This is combined with a lack of guidance from senior members of the profession on the purpose of student electives, which, if undertaken properly, are very valuable. Sadly, it also stems from the idea that people living in the developing world are a population of second-class citizens, who, because of their economic predicament, have no choice but to accept the second-rate skills of unqualified students, and who deserve to be taken advantage of in this way.

We feel strongly that active intervention is required on the part of Medical School Deans to combat this atmosphere of 'medical colonialism'.

We appeal to all students embarking on an elective to consider carefully what ought and ought not to be gained from it. Above all, it must be remembered that as a nation we owe our economic success at least partly to the exploitation of underdeveloped countries, and that in accepting us for an elective, it is once again they who are doing us the favour.

Have we really come this far in achieving the ethical standards we claim to be so proud of, only to wave goodbye to them all at Heathrow airport?

TIM A HOLT, TONY J ADAMS

St George's Hospital Medical School, Cranmer Terrace, Tooting, London SW17 ORE 